RESEARCH ARTICLE

\title{
Characterization of Substitution Mutations of elF4G Gene Generated through Adenine Base Editors in Rice
}

\author{
Yaiphabi Kumam ${ }^{1}$, Rajadurai $\mathbf{G}^{1}$, Kumar K K ${ }^{1}$, Varanavasiappan $\mathbf{S}^{1}$, Raveendran $\mathbf{M}^{1}$, Manonmani $\mathbf{S}^{2}$, \\ Gopalakrishnan $\mathbf{C}^{3}$, Arul $\mathrm{L}^{1}$, Kokiladevi $\mathrm{E}^{1}$ and Sudhakar $\mathrm{D}^{1 *}$ \\ ${ }^{1}$ Department of Plant Biotechnology, Centre for Plant Molecular Biology \& Biotechnology, \\ Tamil Nadu Agricultural University, Coimbatore-641 003 \\ ${ }^{2}$ Department of Plant Genetic Resources, Centre for Plant Breeding \& Genetics, \\ Tamil Nadu Agricultural University, Coimbatore-641 003 \\ ${ }^{3}$ Department of Rice, Centre for Plant Breeding \& Genetics, Tamil Nadu Agricultural University, Coimbatore-641 003
}

\begin{abstract}
Adenine base editor ( $\mathrm{ABE}$ ) creates $\mathrm{A}$ to $\mathrm{G}$ transitions within its editing window. In the present study, an ABE was used to target a stretch of six amino acid residues, VLFPNL in translation initiation factor four gamma (elF4G) gene of rice. Agrobacterium-mediated transformation of rice cultivar ASD16 resulted in TO events with high mutation efficiency of $89.29 \%$. Substitution mutations of $A>G$ occurred within the editing window of four to eight bases at $A_{7}>$ $\mathrm{G}_{7}(74.67 \%)$ and $A_{4}>G_{4}(2.46 \%)$. Non-canonical substitutions of $G>C / A$ was also observed at $G_{15}>C_{15}(9.29 \%)$ and $G_{8}>A_{8}(1.15 \%)$. A total of 15 missense base substitution events affecting the target residue was identified. Taken together, the present study showed that ABEs create unexpected base substitutions besides efficient canonical editing of $A>G$ in the rice genome.
\end{abstract}

Keywords: Rice; Adenine base editors; elF4G

\section{INTRODUCTION}

Genome editing by CRISPR/Cas technology has never ceased to evolve, making it the most attractive tool of the $21^{\text {st }}$ century. It has proved to be remarkably successful in creating targeted insertion and deletion mutants across species (Feng et al., 2013; Yang et al., 2014; Kang et al., 2016; Sun et al., 2017; Roberts and Barrangou, 2020). These indel mutations result from double-stranded breaks at the target site that are predominantly repaired by non-homologous end joining (Maruyama et al., 2015; Kosicki et al., 2013). The repair, albeit precise, is error-prone, with no control over the number of nucleotide bases being deleted or inserted, leading to unanticipated mutants (Manghwar et al., 2019; Maruyama et al., 2015; Piergentili et al., 2021). More recently, base-editing technology, comprising of cytosine base editors (CBEs) and adenine base editors (ABEs) have refined CRISPR/Cas 9 by performing irreversible substitutions of $C \cdot G$ to $T \cdot A$ (Komor et al., 2013) and A·T to G·C (Gaudelli et al., 2017) base pairs respectively. These substitutions take place exclusively within the editing window and thus are highly precise in targeting human cells (Komor et al., 2013), mouse cells (Gaudelli et al., 2017), bacterial cells (Zheng et al., 2018) and crop species (Qin et al., 2020; Veillet et al., 2020; Wang et al., 2020: Wu et al., 2020).

Corresponding author mail id: dsudhakar@hotmail.com
Both CBEs and ABEs have made their significant contributions in editing essential genes that govern the agronomic performance in rice, including nutritional improvement (Li et al., 2018), plant architecture and grain yield (Zong et al., 2017; Hua et al., 2018, 2019) and high nitrogen use efficiency (Lu and Zhu, 2017). In addition to these, they have been used to target genes responsible for imparting herbicide resistance (Shimatani et al., 2017, Li et al., 2018) and blast resistance (Ren et al., 2018) in rice. Of these two systems of base editors, CBEs have been reported to have a higher off-target mutation that arises from cytosine deaminases coupled with low editing efficiency. Thus, ABE is the preferred choice for gene editing in rice (Hao et al., 2019; Jin et al., 2019).

ABE7.10, an adenine base editor, is widely used for editing $A \cdot T$ to $G \cdot C$ base pair with high fidelity within an activity window of $4-8$ bp of the sgRNA sequence (with reference to the protospacer adjacent motif (PAM) at positions 21 to 23) (Kim et al., 2019). Li et al.(2018) modified this vector to yield maximum $A$ to $G$ editing by using the construct pH-PABE-7-esgRNA in rice and thus achieved high editing efficiency, up to $59.1 \%$ in a japonica variety, Zhonghua 11. Earlier reports on mutations in translation initiation factor four gamma (elF4G) gene, leading to substitution or in-frame deletions at

$107 \mid 10-12$ | 1 
amino acid residues viz., $\mathrm{Y}^{1059} \mathrm{~V}^{1060}$ have been shown to confer resistance against rice tungro spherical virus (RTSV) in naturally occurring RTSV resistant genotypes (Lee et al., 2010). Subsequent in-frame mutations upstream of the YV residue spanning across SVLFPNLAGKS (amino acid positions 1046 to 1058) and especially $\mathrm{N}^{1051} \mathrm{~L}^{1052}$ imparted resistance against RTSV (Macovei et al., 2018). Thus, in the present study, we attempted to create targeted novel modifications in VLFPNL residues in an elite tungro susceptible indica cultivar, ASD16 using the ABE construct, pH-PABE-7-esgRNA.

\section{MATERIAL AND METHODS}

\section{Design and development of plant adenine base editing vector}

A single guide RNA (sgRNA) in translation initiation factor 4 gamma (elF4G) gene of indica variety (BGIOSGA025931; Ensemble Plants), targeting the VLFPNL residue was designed using the Chop-Chop tool (Labun et al., 2016). To the sgRNA sequences (Top strand: 5'-ACAAATTAGGGAACAGAACGC -3' and Bottom strand: 5' GCGTTCTGTTCCCTAATTTGT -3'), Bsal adaptors (5' GGCG in the top strand and 5'AAAC in the bottom strand) were added for DNA oligomer synthesis (Eurofins, Bengaluru). The synthesized DNA oligomers were duplexed and cloned into the $B$ sal restriction site of the binary vector, pH-PABE-7esgRNA, a gift from Dr. Caixia Gao (Addgene plasmid \# 115620; http://n2t.net/addgene:115620; RRID: Addgene_115620) (Li et al., 2018). This clone was mobilized into Agrobacterium strain, LBA4404. T-DNA of the binary plant expression vector, harboring the sgRNA is represented in Fig. 1.

\section{Agrobacterium-mediated transformation of ASD16}

ASD16, an elite medium duration indica rice variety that is widely grown in Tamil Nadu was chosen as a target genotype. Immature embryos were used for Agrobacterium-mediated transformation of ASD16 (Hiei and Komari, 2008) with the construct based on the plant ABE vector. Friable yellow calli that survived two rounds of stringent selection in 50 $\mathrm{mgL}^{-1}$ hygromycin antibiotic successfully regenerated into complete plants. The regenerated plants were hardened and maintained in transgenic greenhouse. The transformation efficiency (in percentage) of the construct used was calculated using the formula,

$\begin{aligned} & \text { Transformation } \\ & \text { efficiency }\end{aligned}=\frac{\begin{array}{l}\text { Number of co-cultivated } \\ \text { embryos that produced plants }\end{array}}{\text { Total number of embryos co- }}$
cultivated

Plant genomic DNA from young leaves of putative mutants and ASD16 wild type were isolated using the CTAB method (Porebski et al., 1997). Molecular analyses by PCR for T-DNA presence using sequence-specific primers for hpt (hygromycin phosphotransferase) and cas9 genes (Table 1) were performed. The target region encompassing the sgRNA sequence in the PCR positive mutants was amplified using elF4G gene-specific primers (Table 1). The PCR amplicons were purified (Nucleospin Gel and PCR Purification Kit, Machery Nagel) and sequenced using Sanger sequencing method (Eurofins, Bengaluru).

Figure 1. T-DNA of binary vector pH-PABE-7esgRNA with sgRNA

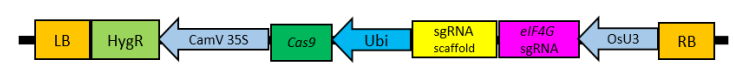

Results obtained from sequencing were analyzed using web-based softwares, DSDecodeM (http://skl. scau.edu.cn/dsdecode/) (Xie et al., 2017; Liu et al., 2015) to decode substitutions in the target region in both alleles of the gene and CRISPR-ID (http:// crispid.gbiomed.kuleuven.be/) (Dehairs et al., 2016) to identify the localization of the mutation along the entire length of the amplified sequence. Besides these softwares, the percentage contribution of a base in substituting its target base was calculated by using an online web-based tool, EditR (http:// baseeditr.com) (Kluesner et al., 2018). The corresponding protein sequences were translated using an online translation tool, Expasy (https:// www.expasy.org). Mutants were identified from analysis of the sequencing results and mutation efficiency (in percentage) was calculated as given below,

$\begin{aligned} & \text { Mutation } \\ & \text { efficiency }\end{aligned}=\frac{\text { Number of events with mutations }}{\text { Total number of events generated }} \times 100$

\section{RESULTS AND DISCUSSION}

\section{Agrobacterium-mediated transformation of ASD16}

Agrobacterium-mediated transformation of ASD16 was performed using the Agrobacterium strain, LBA4404 harboring pH-PABE7-esgRNAelF4G construct. Thirteen batches of co-cultivation, consisting of 1391 immature embryos were performed. A total of 112 independent events was generated, giving transformation efficiency of 8.20 $\%$ (Table 2).

\section{Characterization of mutants generated}

Molecular analysis by PCR for the presence of cas 9 and hpt genes in the 112 independent events confirmed that all the mutants were positive for these genes (Fig. $2 a$ and $2 b$ ). Sanger sequencing analysis of these PCR positive events identified 100 
mutants out of 112 , thus giving a high mutation efficiency of $89.29 \%$ (Table 2). However, the majority of the mutants, comprising of 85 events had silent mutations, and only 15 had missense mutations. These 15 missense mutants had base substitutions affecting the SVLFPNLAGKS residues. Earlier reports by Macovei et al. (2018) suggested that mutations affecting the above stretch of 11 amino acid residues can impart resistance against tungro disease. Hence, the 15 missense mutants were the promising outcome of the experiment (Table 2). A $>\mathrm{G}$ substitutions occurred at two positions of the sgRNA sequence, $A_{7}$ and $A_{4}$, where $74.68 \%$ and $2.4 \%$ of adenosines were converted to guanosines respectively (Fig. $3 \& 4$ ). In addition to this, $A_{7}>$
$\mathrm{G}_{7}$ was observed in homozygous conditions in 42 $\mathrm{T}_{0}$ independent events, while only mono-allelic substitution was observed at $A_{4}$. The mechanism attributing to this exceptionally biased preference of base substitution of $A_{7}$, yielding large number of homozygous mutants in $T_{0}$ generation remains unclear. However, this may partly be attributed to the sequences that are present immediately adjacent to the adenine residue, as sgRNAs from different genomic loci respond distinctively to adenine base editing (Li et al., 2018). The sgRNA used in the present study has $A_{7}$ succeeded by three Gs viz., $G_{8} G_{9} G_{10}$. This suggests the possible influence of flanking bases on the performance of the base editors.

Table 1. Primers and PCR conditions used in the study

\begin{tabular}{|c|c|c|c|c|}
\hline $\begin{array}{l}\text { Name of } \\
\text { gene }\end{array}$ & Forward $(F)$ and reverse $(R)$ primers (5' to $\left.3^{\prime}\right)$ & $\begin{array}{l}\text { Amplicon } \\
\text { size (in bp) }\end{array}$ & PCR conditions & \\
\hline hpt & $\begin{array}{l}\text { hpt F: GCTGTTATGCGGCCATTGGTC } \\
\text { hpt R: GCCTCCAGAAGAAGATGTTG }\end{array}$ & 686 & $\begin{array}{l}94^{\circ} \mathrm{C} \text { for } 5 \mathrm{~min} \\
94^{\circ} \mathrm{C} \text { for } 1 \mathrm{~min} \\
58^{\circ} \mathrm{C} \text { for } 30 \mathrm{~s} \\
72^{\circ} \mathrm{C} \text { for } 30 \mathrm{~s} \\
72^{\circ} \mathrm{C} \text { for } 2 \mathrm{~min}\end{array}$ & $\begin{array}{l}35 \\
\text { cycles }\end{array}$ \\
\hline cas 9 & $\begin{array}{l}\text { cas9 F: ACTAACTCTGTTGGCTGGGC } \\
\text { cas9 R: GCGCAATGAGATTCCCGAAC }\end{array}$ & 694 & $\begin{array}{l}95^{\circ} \mathrm{C} \text { for } 5 \mathrm{~min} \\
95^{\circ} \mathrm{C} \text { for } 45 \mathrm{~s} \\
58^{\circ} \mathrm{C} \text { for } 45 \mathrm{~s} \\
72^{\circ} \mathrm{C} \text { for } 45 \mathrm{~s} \\
72^{\circ} \mathrm{C} \text { for } 10 \mathrm{~min}\end{array}$ & $\begin{array}{l}30 \\
\text { cycles }\end{array}$ \\
\hline elF4G & $\begin{array}{l}\text { elF4G F: AAGACTTTCCGGCCAAATTA } \\
\text { elF4G R: TAATTTGGCCGGAAAGTCTT }\end{array}$ & 577 & $\begin{array}{l}95^{\circ} \mathrm{C} \text { for } 5 \mathrm{~min} \\
95^{\circ} \mathrm{C} \text { for } 45 \mathrm{~s} \\
53^{\circ} \mathrm{C} \text { for } 1 \mathrm{~min} \\
72^{\circ} \mathrm{C} \text { for } 45 \mathrm{~s} \\
72^{\circ} \mathrm{C} \text { for } 2 \mathrm{~min}\end{array}$ & $\begin{array}{l}30 \\
\text { cycles }\end{array}$ \\
\hline
\end{tabular}

More recently, ABEs have been found to induce conversion of cytosine residue to guanine and thymine within its activity window in human and mouse cells (Lee et al., 2018; Kim et al., 2019, Jeong et al., 2020). This has questioned the exemption of ABEs from yielding unanticipated mutants, although in negligible percentage (Li et al., 2018). In support of this, an intriguing observation based on this

Figure 2a. PCR analysis of putative mutants for the presence of hpt gene

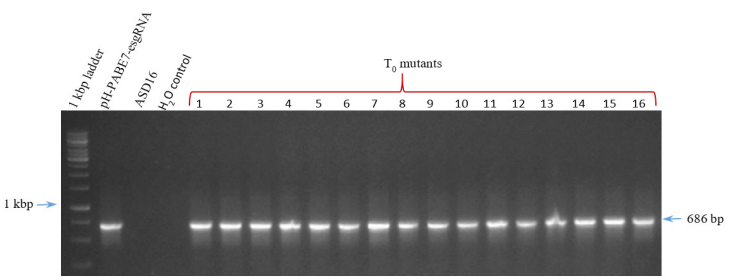

experiment is the non-canonical substitution of $C \cdot G$ to $\mathrm{G} \cdot \mathrm{C}$ other than the expected $\mathrm{A}>\mathrm{G}$ substitution. Unanticipated mutations in the sgRNA region were as well observed at positions $G_{15}>C_{15}(9.29 \%)$ and $G_{8}>A_{8}(1.15 \%)$ (Fig. 3 and Fig. 5). Examination of previous reports on $A B E 7.10$ series of adenine base editors in editing non-target bases showed that the deaminase enzyme used in the construction of

Figure 2b. PCR analysis of putative mutants for the presence of cas 9 gene

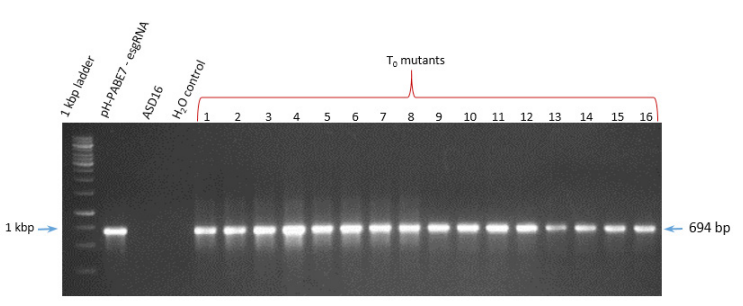


ABE 7.10 from E. coli (ecTadA, E. coli tRNA Specific Adenosine deaminase) harbors common catalytic site for deamination of both cytosine and adenine residues (Jeong et al., 2020). As a result, cytosine conversions to $G / T / A$ residues were observed using an ABE 7.10 in human and mouse cells. This,

Figure 3. Percent nucleotide changes at each base position of the target sequence

\begin{tabular}{|c|c|c|c|c|c|c|c|c|c|c|c|c|c|c|c|c|c|c|c|c|}
\hline & & & & & & & & & & & & & & & & & & & & \\
\hline & $\mathrm{C}_{1}$ & $\mathrm{~A}_{2}$ & $A_{3}$ & $\mathrm{~A}_{4}$ & $T_{5}$ & $\mathrm{~T}_{6}$ & $A_{7}$ & $\mathrm{G}_{8}$ & $\mathrm{G}_{9}$ & $\mathrm{G}_{10}$ & $A_{11}$ & $A_{12}$ & $\mathrm{C}_{13}$ & $A_{14}$ & $\mathrm{G}_{15}$ & $A_{16}$ & $A_{17}$ & $\mathrm{C}_{18}$ & $\mathrm{G}_{19}$ & $\mathrm{C}_{20}$ \\
\hline A & 0 & $\begin{array}{l}99.6 \\
8\end{array}$ & $\begin{array}{l}99.0 \\
3\end{array}$ & $\begin{array}{l}97.5 \\
4\end{array}$ & 0 & 0.64 & $\begin{array}{l}25.7 \\
6\end{array}$ & 1.15 & 0 & 0.38 & $\begin{array}{l}99.9 \\
9\end{array}$ & $\begin{array}{l}99.4 \\
9\end{array}$ & 0 & $\begin{array}{l}10 \\
0 \\
\end{array}$ & 0.47 & $\begin{array}{l}99.7 \\
9\end{array}$ & $\begin{array}{l}99.5 \\
9 \\
\end{array}$ & 0 & & 0 \\
\hline C & 100 & 0 & 0.60 & 0 & 0 & 0 & 0 & 0 & 0 & 0 & 0 & 0 & $\begin{array}{l}10 \\
0\end{array}$ & 0 & 9.29 & 0 & 0 & $\begin{array}{l}10 \\
0\end{array}$ & 0 & $\begin{array}{l}10 \\
0\end{array}$ \\
\hline $\mathrm{G}$ & 0 & 0.32 & 0.37 & 2.46 & 0 & 0.17 & $\begin{array}{l}74.6 \\
8 \\
\end{array}$ & $\begin{array}{l}98.3 \\
9\end{array}$ & 100 & $\begin{array}{l}99.6 \\
2\end{array}$ & 0.01 & 0.51 & 0 & 0 & $\begin{array}{l}90.2 \\
4\end{array}$ & 0.19 & 0.35 & 0 & $\begin{array}{l}10 \\
0\end{array}$ & 0 \\
\hline$T$ & 0 & 0 & 0 & 0 & 100 & $\begin{array}{l}99.1 \\
9\end{array}$ & 0 & 0.46 & 0 & 0 & 0 & 0 & 0 & 0 & 0 & 0.02 & 0.06 & 0 & 0 & 0 \\
\hline
\end{tabular}

(The arrows indicate the expected base substitution of $A>G$ )

however was restricted to a narrow editing window of 5-7 bp, provided that the cytosine base was positioned in a specific $\mathrm{TC} * \mathrm{~N}$ residue (Lee et al., 2018, Kim et al., 2019). Lee et al. (2018) have also discussed the concept of opposite strand editing, as they observed high $G \cdot A$ mutations, which may be due to $C \cdot T$ conversions on the opposite strand when they used CBEs. This opposite strand editing,

Figure 4. Mutations observed at different nucleotide positions and corresponding protein sequences of the missense events generated. (Subtitutions are denoted in red. A1: Allele 1; A2: Allele 2; WT: Wild Type)

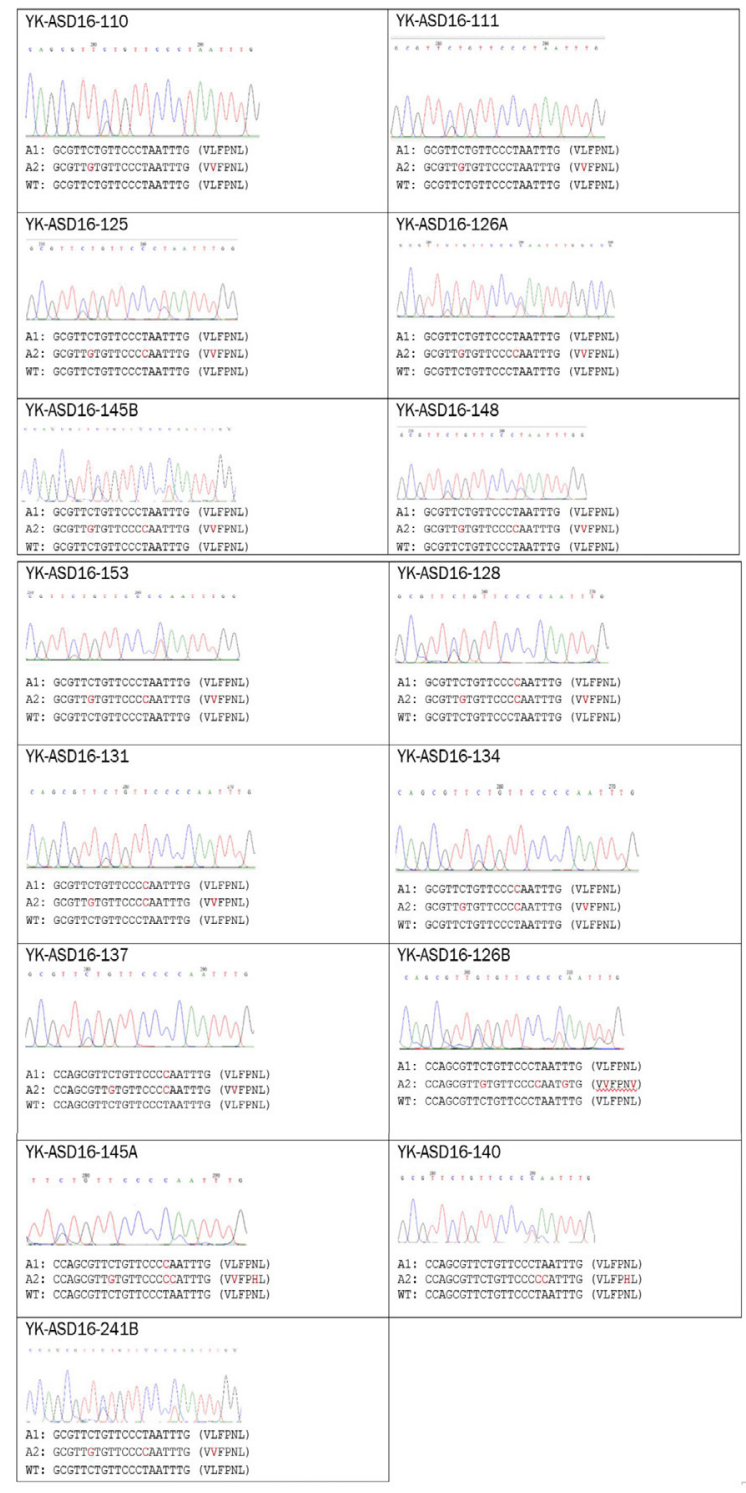


however, occurred only outside the editing window, also termed as bystander editing. Our observations of $G_{15}>C_{15}$ and $G_{8}>C_{8}$ in the target strand corresponds to $C_{15}>G_{15}$ and $C_{8}>G_{8}$ editing on the opposite strand. This can be considered as a case of opposite strand bystander editing. The editing at $G_{8}$, however does not follow the $T C * N$ trend. Instead, it was observed in a $\mathrm{N} * \mathrm{CT}$ fashion. Insights

Table 2. Agrobacterium-mediated transformation of rice cultivar ASD16 and mutations events generated

\begin{tabular}{ccccccc}
\hline $\begin{array}{c}\text { No. of } \\
\text { batches co- } \\
\text { cultivated }\end{array}$ & $\begin{array}{c}\text { No. of immature } \\
\text { embryos co- } \\
\text { cultivated }\end{array}$ & $\begin{array}{c}\text { No. of } \\
\text { events } \\
\text { generated }\end{array}$ & $\begin{array}{c}\text { Transformation } \\
\text { efficiency (\%) }\end{array}$ & $\begin{array}{c}\text { Events with } \\
\text { missense } \\
\text { mutations }\end{array}$ & $\begin{array}{c}\text { Events } \\
\text { with silent } \\
\text { mutations }\end{array}$ & $\begin{array}{c}\text { Mutation } \\
\text { Frequency (\%) }\end{array}$ \\
\hline 13 & 1391 & 112 & 8.20 & 15 & 85 & 89.29 \\
\hline
\end{tabular}

on unexpected edits with base editors, presumably regarded to be highly specific have opened up newer possibilities in genome editing. Jeong's group has acknowledged that bystander editing of cytosines using ABEs are not out of the ordinary. They proposed that the probability of such an occurrence could be reduced by engineering the ecTadA enzyme. Their work on a series of ecTadA enzyme mutants with

Figure 5. C substitutions on the opposite strand (3' to 5')

\begin{tabular}{|l|l|l|l|l|l|l|l|l|l|l|l|l|l|l|l|l|l|l|l|l|l|l|}
\hline $\begin{array}{l}\text { Target strand } \\
\text { 5' to 3' }\end{array}$ & $\mathrm{C}_{1}$ & $\mathrm{~A}_{2}$ & $\mathrm{~A}_{3}$ & $\mathrm{~A}_{4}$ & $\mathrm{~T}_{5}$ & $\mathrm{~T}_{6}$ & $\mathrm{~A}_{7}$ & $\begin{array}{l}\mathrm{G}_{8} \\
(\mathrm{G}>\mathrm{A})\end{array}$ & $\mathrm{G}_{9}$ & $\mathrm{G}_{10}$ & $\mathrm{~A}_{11}$ & $\mathrm{~A}_{12}$ & $\mathrm{C}_{13}$ & $\mathrm{~A}_{14}$ & $\begin{array}{l}\mathrm{G}_{15} \\
(\mathrm{G}>\mathrm{C})\end{array}$ & $\mathrm{A}_{16}$ & $\mathrm{~A}_{17}$ & $\mathrm{C}_{18}$ & $\mathrm{G}_{19}$ & $\mathrm{C}_{20}$ & $\mathrm{~T}_{21} \mathrm{G}_{22} \mathrm{G}_{23}$ \\
\hline $\begin{array}{l}\text { Complimentary } \\
\text { 3' to 5 }\end{array}$ & $\mathrm{G}$ & $\mathrm{T}$ & $\mathrm{T}$ & $\mathrm{T}$ & $\mathrm{A}$ & $\mathrm{A}$ & $\mathrm{T}$ & $\begin{array}{l}\mathrm{C} \\
(\mathrm{C}>\mathrm{T})\end{array}$ & $\mathrm{C}$ & $\mathrm{C}$ & $\mathrm{T}$ & $\mathrm{T}$ & $\mathrm{G}$ & $\mathrm{T}$ & $\begin{array}{l}\mathrm{C} \\
(\mathrm{C}>\mathrm{G})\end{array}$ & $\mathrm{T}$ & $\mathrm{T}$ & $\mathrm{G}$ & $\mathrm{C}$ & $\mathrm{G}$ & $\mathrm{ACC}$ \\
\hline
\end{tabular}

$\left(G_{8}>C_{8}\right.$ and $G_{15}>C_{15}$ when analysed on the complimentary strand corresponds to base substitutions of $C>T$ and $C>G$.)

key modifications at specific amino acid positions have shown that cytosine deaminase activity of the enzyme could be fine-tuned to increase or decrease cytosine catalysis activity (Jeong et al., 2020). Being in the preliminary stage of application, dedicated research to understand the molecular mechanisms of actions of ecTadA enzyme has to be carried out.

\section{CONCLUSION}

The present study, based on the application of an adenine base editing vector to target a host translation initiation factor, elF4G gene in indica rice ASD16, successfully identified 15 mutants with missense mutations. These 15 missense mutants had nucleotide substitutions affecting the VLFPNL residue and are promising candidates that will impart resistance against tungro disease. based on earlier reports of Lee et al. (2010) and Macovei et al. (2018). Progeny analysis needs to be carried out to identify homozygous mutants by raising subsequent $T_{1}$ and $T_{2}$ generations. Bioassay on these homozygous mutants would prove the level of resistance imparted by the substitution of the target residues.

\section{FUNDING AND ACKNOWLEDGMENT}

The authors would like to thank ICAR-NASF (ICAR/CRISPR-Cas-7003/2017-18) for the funding and Centre for Plant Molecular Biology and Biotechnology, Tamil Nadu Agricultural University, Coimbatore for providing facilities. YK also thank ICAR-NASF for the fellowship.

\section{REFERENCES}

Dehairs, J., Talebi, A., Cherifi, Y. and J. V. Swinnen. 2016. "CRISP-ID: decoding CRISPR mediated indels by Sanger sequencing." Sci. Rep. 6(1): 1-5.

Feng, Z., Mao, Y., Xu, N., Zhang, B., Wei, P., Yang, D.-L., Wang, Z., Zhang, Z., Zheng, R and L. Yang, 2014. Multigeneration analysis reveals the inheritance, specificity, and patterns of CRISPR/Cas-induced gene modifications in Arabidopsis. Proc. Natl. Acad. Sci., 111(12): 4632-4637.

Gaudelli, N. M., Komor, A. C., Rees, H. A., Packer, M. S., Badran, A. H., Bryson, D. I., and Liu, D. R. 2017. Programmable base editing of A. T to $G$. $C$ in genomic DNA without DNA cleavage. Nature, 551(7681): 464-471.

Hao, L., Ruiying, Q., Xiaoshuang, L., Shengxiang, L., Rongfang, X., Jianbo, Y., and Pengcheng, W. 2019. CRISPR/Cas9-mediated adenine base editing in rice genome. Rice Sci., 26(2): 125-128.

Hiei, Y., and Komari, T. 2008. Agrobacterium-mediated transformation of rice using immature embryos or calli induced from mature seed. Nat. Protoc., 3(5): 824-834.

Hua, K., Tao, X., Liang, W., Zhang, Z., Gou, R., and Zhu, J. K. 2020. Simplified adenine base editors improve adenine base editing efficiency in rice. Plant Biotechnol. J., 18(3): 770-778.

Jeong, Y. K., Lee, S., Hwang, G. H., Hong, S. A., Park, S. E., Kim, J. S., Woo J. S. and Bae, S. (2020). Precise adenine base editors that exhibit minimized cytosine catalysis. Nat. Biotechnol.,1: 1-8.

Jin, S., Zong, Y., Gao, Q., Zhu, Z., Wang, Y., Qin, P., Liang, C. Wang, D., Qiu, J. L. and Zhang, F. 2019. Cytosine, but not adenine, base editors induce genome-wide off-target mutations in rice. Sci., 
364(37): 292-295.

Kang, X., He, W., Huang, Y., Yu, Q., Chen, Y., Gao, X., Sun, $X$. and Fan, Y. 2016. Introducing precise genetic modifications into human 3PN embryos by CRISPR/Cas-mediated genome editing. J. Assist. Reprod. Genet., 33(5): 581-588.

Kim, H. S., Jeong, Y. K., Hur, J. K., Kim, J. S., and Bae, S. 2019. Adenine base editors catalyze cytosine conversions in human cells. Nat. Biotechnol., 37(10): 1145-1148.

Kluesner, M. G., Nedveck, D. A., Lahr, W. S., Garbe, J. R., Abrahante, J. E., Webber, B. R., and Moriarity, B. S. 2018. EditR: a method to quantify base editing from Sanger sequencing. CRISPR J., 1(3): 239-250.

Komor, A. C., Kim, Y. B., Packer, M. S., Zuris, J. A., and Liu, D. R. 2016. Programmable editing of a target base in genomic DNA without double-stranded DNA cleavage. Nature, 533(7603): 420-424.

Kosicki, M., Tomberg, K., and Bradley, A. 2018. Repair of double-strand breaks induced by CRISPRCas9 leads to large deletions and complex rearrangements. Nat. Biotechnol., 36(8): 765-771.

Labun, K., Montague, T. G., Gagnon, J. A., Thyme, S. B., and Valen, E. 2016. CHOPCHOP v2: a web tool for the next generation of CRISPR genome engineering. Nucleic Acids Res., 44(W1): W272-W276.

Lee, J.-H., Muhsin, M., Atienza, G. A., Kwak, D.-Y., Kim, S.-M., De Leon, T. B., Angeles, E. R., Coloquio, E., Kondoh, H. and Satoh, K. 2010. Single nucleotide polymorphisms in a gene for translation initiation factor (elF4G) of rice (Oryza sativa) associated with resistance to Rice tungro spherical virus. Mol. Plant-microbe Interact., 23(1): 29-38.

Lee, H. K., Willi, M., Miller, S. M., Kim, S., Liu, C., Liu, D. R., and Hennighausen, L. 2018. Targeting fidelity of adenine and cytosine base editors in mouse embryos. Nat. Commun., 9(1): 1-6.

Li, C., Zong, Y., Wang, Y., Jin, S., Zhang, D., Song, Q., Zhang, R. and Gao, C. 2018. Expanded base editing in rice and wheat using a Cas9-adenosine deaminase fusion. Genome Bio., 19(1): 1-9.

Liu, Hao, Yuduan Ding, Yanqing Zhou, Wenqi Jin, Kabin Xie, and Ling-Ling Chen. 2017. "CRISPR-P 2.0: an improved CRISPR-Cas9 tool for genome editing in plants." Mol. Plant, 10(3): 530-532.

Liu, W., Xie X., Ma, X., Li, J., Chen, J. and Liu, Y-G. 2015. "DSDecode: a web-based tool for decoding of sequencing chromatograms for genotyping of targeted mutations." Mol. Plant, 8(9): 1431-1433.

Lu, Y., and Zhu, J.-K. 2017. Precise editing of a target base in the rice genome using a modified CRISPR/ Cas9 system. Mol. Plant, 10(3): 523-525.

Macovei, A., Sevilla, N. R., Cantos, C., Jonson, G. B., Slamet-Loedin, I., Cermak, T., Voytas, D. F., Choi, I. R. and Chadha-Mohanty, P. 2018. Novel alleles of rice elF4G generated by CRISPR/Cas9-targeted mutagenesis confer resistance to Rice tungro spherical virus. Plant Biotechnol. J., 16 (11): 1918-1927.
Manghwar, H., Lindsey, K., Zhang, X., and Jin, S. 2019. CRISPR/Cas system: recent advances and future prospects for genome editing. Trends Plant Sci., 24(12): 1102-1125.

Maruyama, T., Dougan, S. K., Truttmann, M. C., Bilate, A. M., Ingram, J. R. and Ploegh, H. L. 2015. Increasing the efficiency of precise genome editing with CRISPR-Cas 9 by inhibition of non-homologous end joining. Nature Biotechnol., 33(5): 538-542.

Piergentili, R., Del Rio, A., Signore, F., Umani Ronchi, F., Marinelli, E., and Zaami, S. 2021. CRISPR-Cas and its wide-ranging applications: From human genome editing to environmental implications, technical limitations, hazards and bioethical issues. Cells, 10(5), 969.

Porebski, S., Bailey, L. G. and Baum, B. R. 1997. Modification of a CTAB DNA extraction protocol for plants containing high polysaccharide and polyphenol components. Plant Mol. Biol. Rep., 15(1): 8-15.

Qin, L., Li, J., Wang, Q., Xu, Z., Sun, L., Alariqi, M., Manghwar, H., Wang, G., Li, B., Ding, X. and Jin, S. 2020. High-efficient and precise base editing of C. G to T. A in the allotetraploid cotton (Gossypium hirsutum) genome using a modified CRISPR/Cas9 system. Plant Biotechnol. J., 18(1): 45-56.

Ren, B., Yan, F., Kuang, Y., Li, N., Zhang, D., Zhou, X., Lin, $\mathrm{H}$ and Zhou, H. 2018. Improved base editor for efficiently inducing genetic variations in rice with CRISPR/Cas9-guided hyperactive hAID mutant. Mol. Plant, 11(4): 623-626.

Roberts, A., \& Barrangou, R. 2020. Applications of CRISPR-Cas systems in lactic acid bacteria. FEMS Microbiol. Rev., 44(5): 523-537.

Shimatani, Z., Kashojiya, S., Takayama, M., Terada, R., Arazoe, T., Ishii, H., Teramura, H., Yamamoto, T., Komatsu, H. and Miura, K. 2017. Targeted base editing in rice and tomato using a CRISPR-Cas9 cytidine deaminase fusion. Nature Biotechnol., 35(5): 441-443.

Sun, D., Guo, Z., Liu, Y., \& Zhang, Y. 2017. Progress and prospects of CRISPR/Cas systems in insects and other arthropods. Front. Physiol., 8, 608.

Veillet, F., Perrot, L., Guyon-Debast, A., Kermarrec, M. P., Chauvin, L., Chauvin, J. E., Gallois, J. L., Mazier, M. and Nogué, F. 2020. Expanding the CRISPR toolbox in P. patens using SpCas9-NG variant and application for gene and base editing in Solanaceae crops. Int. J. Mol. Sci., 21(3), 1024.

Wang, M., Xu, Z., Gosavi, G., Ren, B., Cao, Y., Kuang, Y., Zhou, X. and Zhou, H. 2020. Targeted base editing in rice with CRISPR/ScCas9 system. Plant Biotechnol. J.,18(8), 1645.

Wu, J., Chen, C., Xian, G., Liu, D., Lin, L., Yin, S., Sun, Q., Fang, Y., Zhang, H. and Wang, Y. 2020. Engineering herbicide-resistant oilseed rape by CRISPR/Cas9mediated cytosine base-editing. Plant Biotechnol. J., 18(9): 1857-1859.

Xie, K., Zhang, J. and Yang, Y. 2014. "Genome-wide prediction of highly specific guide RNA spacers for 
CRISPR-Cas9-mediated genome editing in model plants and major crops." Mol. Plant, 7(5): 923926. doi: $10.1093 / \mathrm{mp} / \mathrm{ssu009}$.

Yang, H., Wang, H. and Jaenisch, R. 2014. Generating genetically modified mice using CRISPR/Casmediated genome engineering. Nature Protoc, 9(8), 1956.
Zheng, K., Wang, Y., Li, N., Jiang, F. F., Wu, C. X., Liu, F., Chen, H. C. and Liu, Z. F. 2018. Highly efficient base editing in bacteria using a Cas9-cytidine deaminase fusion. Commun. Biol., 1(1): 1-6.

Zong, Y., Wang, Y., Li, C., Zhang, R., Chen, K., Ran, Y., Qui, J. L., Wang, D. and Gao, C. (2017). Precise base editing in rice, wheat and maize with a Cas9cytidine deaminase fusion. Nature Biotechnol., 35 (5): 438-440. 